\title{
ANTI-FRAUD STRATEGY
}

\section{Zdravko Todorović́ ${ }^{1}$, Darko Tomaš ${ }^{2}$, Boris Todorović ${ }^{3}$}

date of paper receipt:

06.10.2020.

Original Article date of sending to review:

08.10.2020.

doi: 10.2478/eoik-2020-0010 date of review receipt:

26.10.2020.

UDK 343.53:343.123.5(4-672EU)

\footnotetext{
${ }^{1}$ Faculty of Economics, University of Banja Luka, Bosnia and Herzegovina

${ }^{2}$ Faculty of Economics, University of Banja Luka, Bosnia and Herzegovina

${ }^{3}$ Axelyos, Banja Luka, Bosnia and Herzegovina
}

\begin{abstract}
Fraud is not an individual problem, but rather, we deal with a systematic fraud, particularly in the public sector through the creation of a private monopoly over public sector. Therefore, the first step, which needs to be set in organization in order to develop an efficient system for fraud control is development of anti-fraud strategy. Anti-fraud strategy is based on a policy of integrity and zero tolerance for fraud. Under the fraud we imply: corruption, assets misappropriation and fraudulent statement. Fraudsters are in the organization and beyond. Factors influencing performing of fraud are: pressure, opportunity and rationalization. Costs incurred due to the fraud may be difficult to realistically consider. Battle against fraud is determined by political will, effective legislation and antifraudulent culture and strategy.
\end{abstract}

\section{Keywords:}

Fraud, Anti-fraud strategy, Audit Committee 


\section{INTRODUCTION}

All organizations are vulnerable to fraud (Khadra, Delen 2020). The impact of fraud on states, organizations and citizens is the same: undermining the rule of law, violation of rights, nontransparency of the institution, loss of public resources and weakening of national integrity. That is why fraud and its consequences have become a global problem (Khadra, Delen 2020).

Fraud to the detriment of the organization is in principle carried out for the direct or indirect benefit of employees, persons outside the organization or another organization (Erbuga 2020). Some examples of fraud are: accepting bribes or gifts; diverting a potentially lucrative transaction to an employee or person outside the organization that would otherwise generate profit for the organization; fraud, which is usually the misappropriation of money or property and the falsification of financial information for the purpose of concealing the act, thus making it difficult to detect; intentionally concealing or misrepresenting events, transactions or data; claiming fees for services or goods not actually provided to the organization; intentional failure to take action in situations where a company or law requires action; unauthorized or illegal use of confidential or proprietary information; unauthorized or illegal handling of information networks or operating systems, theft, etc.

The total cost of fraud is difficult to see objectively, and it will be especially difficult to calculate the indirect damages caused by fraud. Some scams will never be detected. Because of this, we can only speak with estimates of fraud losses. The Association of Certified Fraud Examiners (ACFE) published the results of the survey in 2019, based on national reports of fraud. On average, organizations around the world lose $5 \%$ of their annual revenue due to fraud.

Effective fraud resolution requires coordinated and thoughtful action by international, national and local partners who are aware of fraud and the importance of tackling it. States at the national and local levels should enact laws and regulations that will discourage perpetrators of fraud from engaging in the process, and those who do so should be appropriately sanctioned.

The problems of business fraud, which causes a decrease in the profit and assets of the company, and a decrease in reputation, can be eliminated by modeling the process in internal audit to eliminate fraud and establishing an anti-fraud strategy.

\section{THEORETICAL ASPECTS OF RESEARCH}

Fraud has always been happening in all areas of business, and when it comes to money, fraud is of course the most tempting. People engage in various scams, from the smallest ones, seemingly harmless, to those committed by powerful people with great financial consequences (Deb, Sengupta 2020).

Fraud can be defined as any activity whose primary goal is to obtain financial gain in an illegal manner, while causing harm to other persons (Erbuga, 2020). The Association of Certified Fraud Examiners (ACFE, 2019) divides fraud into fraudulent financial reporting, misappropriation of property, and corruption (Figure 1).

According to research conducted by ACFE 2019, embezzlement of funds is the most common fraud, occurring in $85 \%$ of cases but causing the least damage. In contrast, only $9 \%$ of fraud cases committed through financial statements had a median loss of $\$ 1$ million. 
Figure 1. The Fraud Tree

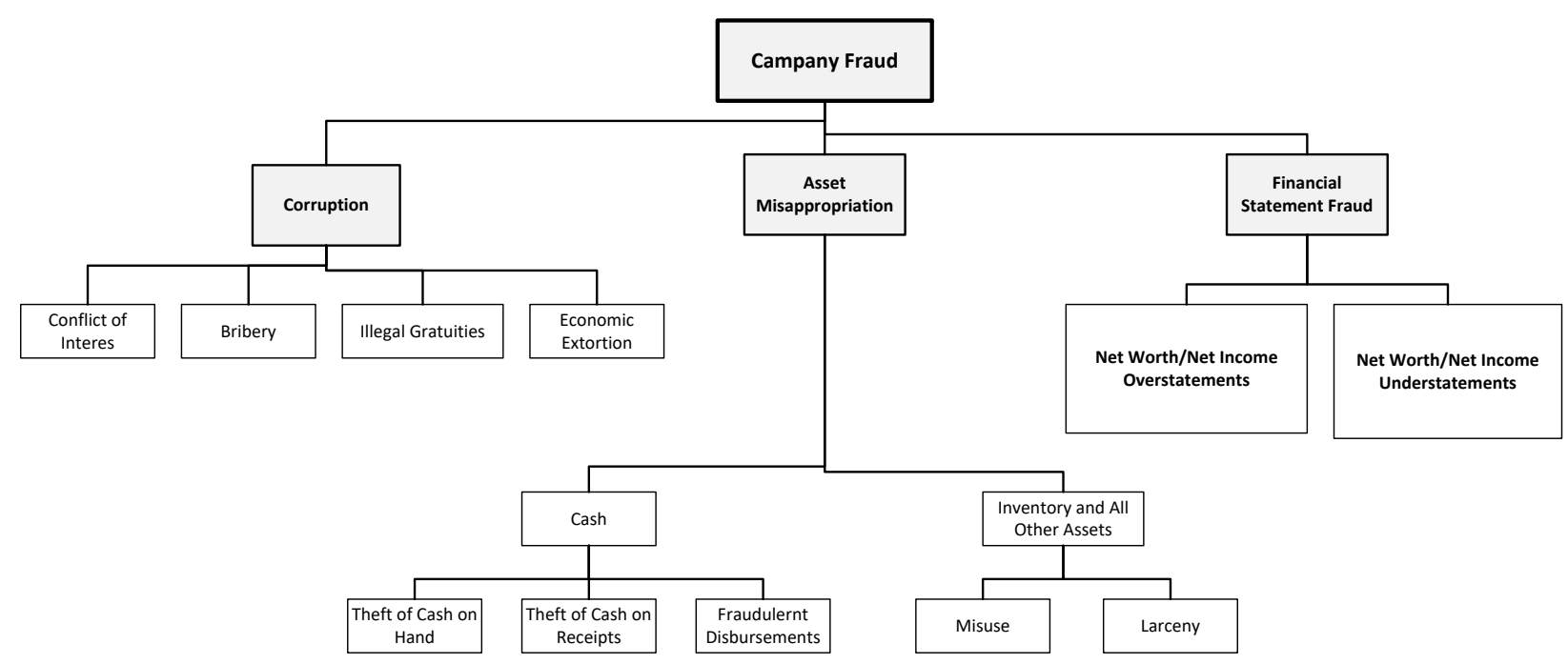

Source: Association of Certified Fraud Examiners, Fraud Tree, 2019.

Edvin Sutherland and Donald Cressey and in 1950 (Sutherland, Cressey 1992) investigated why a person in a trusted position abuses trust and commits fraud. They interviewed the perpetrators of the fraud. After conducting research, on a population of 200 prisoners, they drew the basic conclusion that each fraud has three common factors: pressure (motivation), opportunity (knowledge or ability to commit fraud) and rationalization (justification).

These three factors (Maulidi 2020) that influence the commission of fraud are presented as a triangle of fraud (Homer 2020).

Figure 2. The fraud triangle

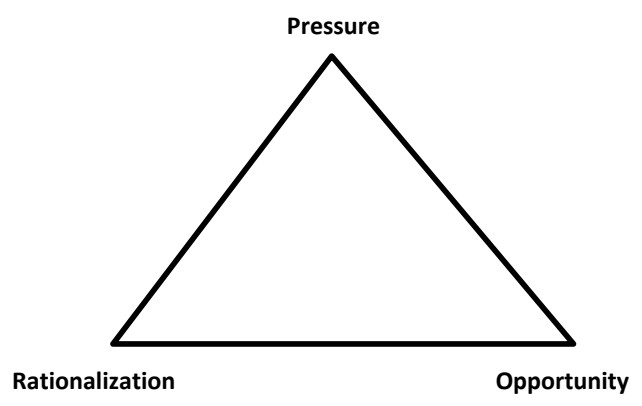

Source: Kurpierz, Smith (2020)

According to the Report of Nations conducted by the Association of Certified Fraud Researchers (ACFE 2019), most perpetrators do not have a criminal record, i.e. 93\% of offenders have never been punished until the fraud is committed.

In a study called "Who is a typical scammer?" (KPMG 2016), we learned about a typical scammer that:

- Male,

- aged between 36 and 45,

- commits fraud against his employer,

- Works in a financial or financial service,

- has a senior managerial position, 
- has been employed in the organization for more than 10 years and

- Works in agreement with other fraudsters.

The research (KPMG 2016) found that the most common fraudsters are people who have confidential information in the organization and who have the opportunity to circumvent controls. It was determined that they are the general director and senior managers working in the financial sector.

There is a reasonable suspicion that fraud and financial scandals are related to weaknesses in corporate governance (Deb, Sengupta, 2020). The publication of inaccurate, «inflated» business results is often associated with the United States primarily because of the biggest corruption scandals that have erupted there, such as: Enron, WorldCom, Tyco International, etc.

Corporate governance has a significant role in improving the efficiency and effectiveness of operations, increasing salaries and the number of employees, improving the quality of financial statements, and increasing investor confidence. Three corporate principles play a key role in the prevention and detection of fraud in financial reporting (Rezaee, Riley, 2014, p. 125):

- Transparency. Ensure that the financial statements are comprehensible and reflect the economic reality of the company.

- Competence and integrity. The effectiveness of corporate governance depends on the integrity and competence of those persons who perform key responsible functions such as supervision, management and control.

- Effective system of competencies and division of responsibilities. The development of an effective management system also depends on the division of competencies and responsibilities between the shareholders' assembly, the board of directors and the management.

Given the frequent corporate fraud (Nawawi, Saiful, Salin, 2018), fraud risk management must contain five key functions (Rezaee, Riley 2014, p.134):

1. Adoption of a policy that will ensure the implementation of programs to eliminate the risk of fraud;

2. Risk assessment of fraud for critical places and persons exposed to the possibility of fraud;

3. Establishment of procedures and methods for fraud prevention;

4. Establish procedures and methods for detecting fraud and

5. Establish a fraud reporting process.

According to the theoretical framework, three basic areas of responsibility of the audit committee are mentioned (Pickett 2019): financial reporting, corporate governance and management control (Figure 3).

From all the above, it follows that the responsibilities of board members are very important because the audit committee must be independent and the members skilled and professional to be able to analyze a large amount of information to monitor the accuracy of reporting for business owners (Bromilow, Berlin 2015). 
Figure 3. Responsibility of the audit committee

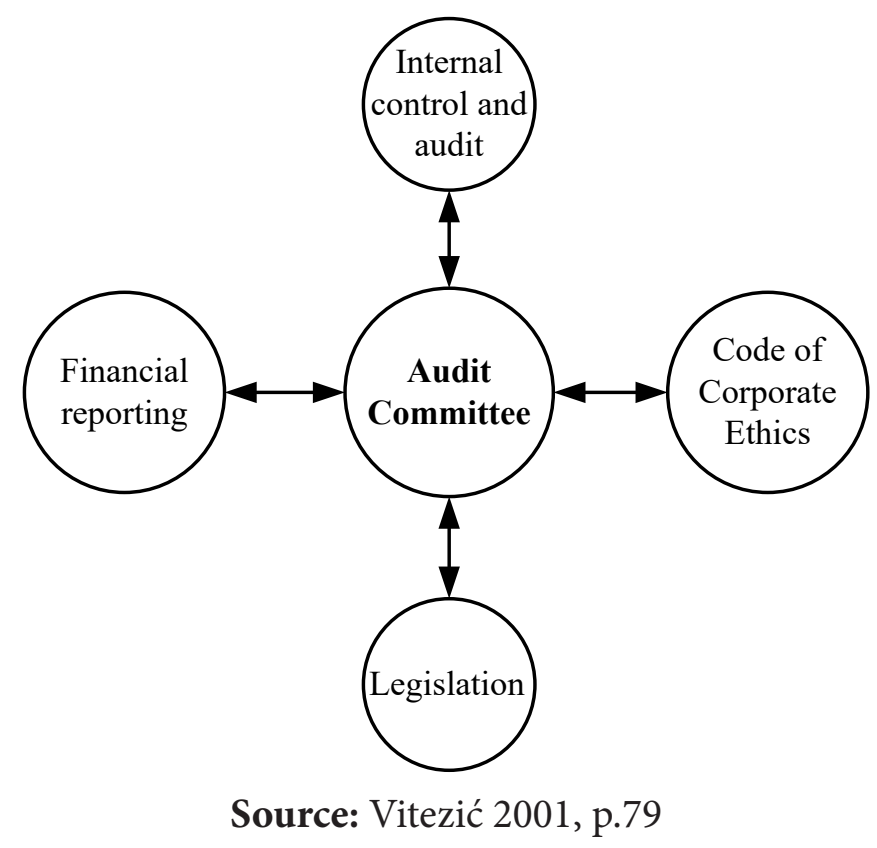

\section{RESEARCH METHODOLOGY AND METHODS}

The paper uses a combined research methodology, i.e. a combination of quantitative and qualitative scientific research methodology. With the quantitative methodology, we collected numerical data, in order to explain, investigate the relationships between variables, to establish causal relationships between the observed phenomena. Through qualitative research, we have collected countless data obtained in the natural environment through extensive observation, interviewing, conversation, whose primary task is to explain the meaning of the observed phenomenon.

Data were collected in the Republic of Srpska public sector.

The interview was conducted based on a structured questionnaire, where specific questions were asked about frauds that were systematically addressed. The proposal of the questionnaire was made in such a way that questions were asked to consider the dependent and independent variables that were related to the prevention and detection of fraud. We asked multiple questions and subquestions for each independent variable.

Additional data was collected by survey. Survey questions were created in such a way that key criteria for fraud prevention were set. The aim of the survey was to expand the data collected by the interview and to improve their quality.

\section{RESEARCH RESULTS}

The assessment of the level of fulfillment of the requirements for the fight against fraud in the public sector in the Republic of Srpska (see Table 1) is 0.34 of the maximum score of 5 . This means that the requirements are not met, and it is necessary to systematically change the approach to combating fraud.

In order to control fraud in the organization, the owners require the board of directors to establish an anti-fraud strategy that will effectively control fraud. The anti-fraud strategy should systematically model the processes in internal audit in order to prevent, detect, investigate, monitor, evaluate and report fraud. 
Table 1. Average level of fulfillment of anti-fraud requirements

\begin{tabular}{|c|c|c|c|}
\hline No. & DESCRIPTION & $\begin{array}{c}\text { Fraud control } \\
\text { rating }\end{array}$ & Maximum rating \\
\hline 1. & $\begin{array}{c}\text { Management and organizational requirements } \\
\text { of fraud control }\end{array}$ & 0,25 & 5,00 \\
\hline 2. & Fraud prevention & 0,71 & 5,00 \\
\hline 3. & Fraud detection & 0,75 & 5,00 \\
\hline 4. & Fraud exploring & 0,00 & 5,00 \\
\hline 5. & Fraud monitoring, evaluation and reporting & 0,00 & 5,00 \\
\hline & AVERAGE & 0,34 & 5,00 \\
\hline
\end{tabular}

Source: authors

In order to implement the anti-fraud strategy, we created an algorithm (Figure 4).

Figure 4. Process model for implementing anti-fraud strategy

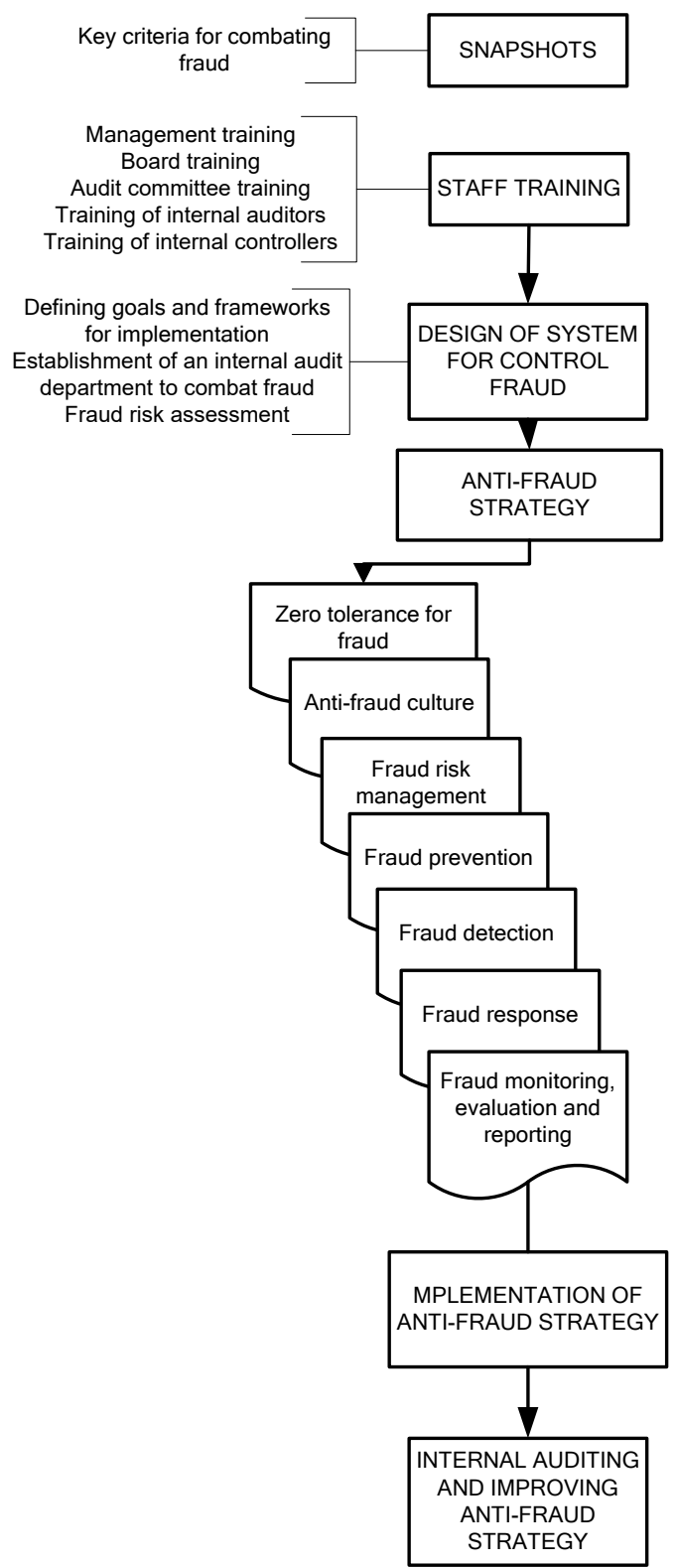

Source: authors 
The model comprises six steps. The first step is a snapshot, which is carried out on the basis of compliance with defined criteria for the fight against fraud. The second step is staff training, in order to raise awareness of the need for a systematic fight against fraud. In the third step, a fraud elimination system is designed, which includes: defining objectives and framework for implementation, establishing an internal audit department to combat fraud and assessing the risk of fraud. The fourth step refers to creating an anti-fraud strategy and making key decisions and documents. Some of them are: adopting a policy on zero tolerance for fraud, defining anti-fraud culture in the code of business ethics, fraud risk assessment, adoption of fraud prevention procedure, adoption of procedure fraud detection, adoption of the fraud response procedure, adoption of the fraud monitoring, evaluation and reporting procedure. The fifth step concerns the implementation of the adopted anti-fraud strategy. And finally, the sixth step is to do internal auditing and improve anti-fraud strategy.

\section{DISCUSSION}

Organizations and authors have approached different approaches to creating a conceptual framework for developing anti-fraud strategies. We will choose three anti-fraud strategies and compare it with the proposal for developing an anti-fraud strategy, which we developed in our research.

In 2012, the Global Management Accountant (CGMA) defined a conceptual framework for developing an anti-fraud strategy that has four main components: Figure 5: prevention, detection, response, and deterrence. To implement an anti-fraud strategy, it is necessary to adhere to the legislative framework, adopt best corporate governance practices based on OECD principles and guidelines, develop an ethical culture and manage risks, especially fraud risks.

Figure 5. Anti-fraud strategy

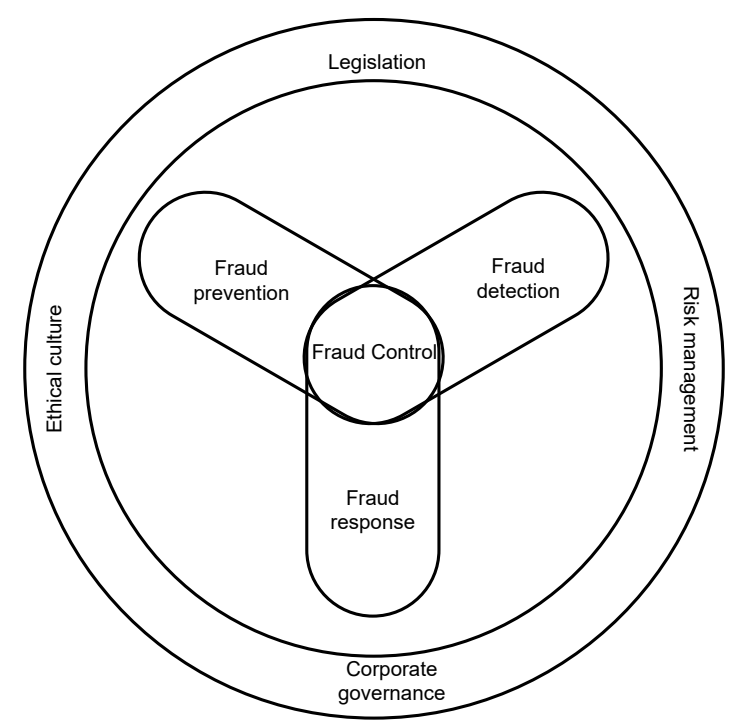

Source: Global Management Accountant (2012) FRAUD RISK MANAGEMENT - a guide to good practice, London

An article entitled «Efficient Fraud Detection in Companies» was published in Tonbeller magazine in 2013, in which the anti-fraud framework was presented. The focus of the observation is the protection of financial reputation, i.e. the fight against fraud. The anti-fraud framework uses all available measures to improve the efficiency of the fraud prevention, detection and response process. Fraud risk management systems use systems to approach the analysis and measurement of fraud risk. Management focuses on the target management and control and supervision of the organization. 


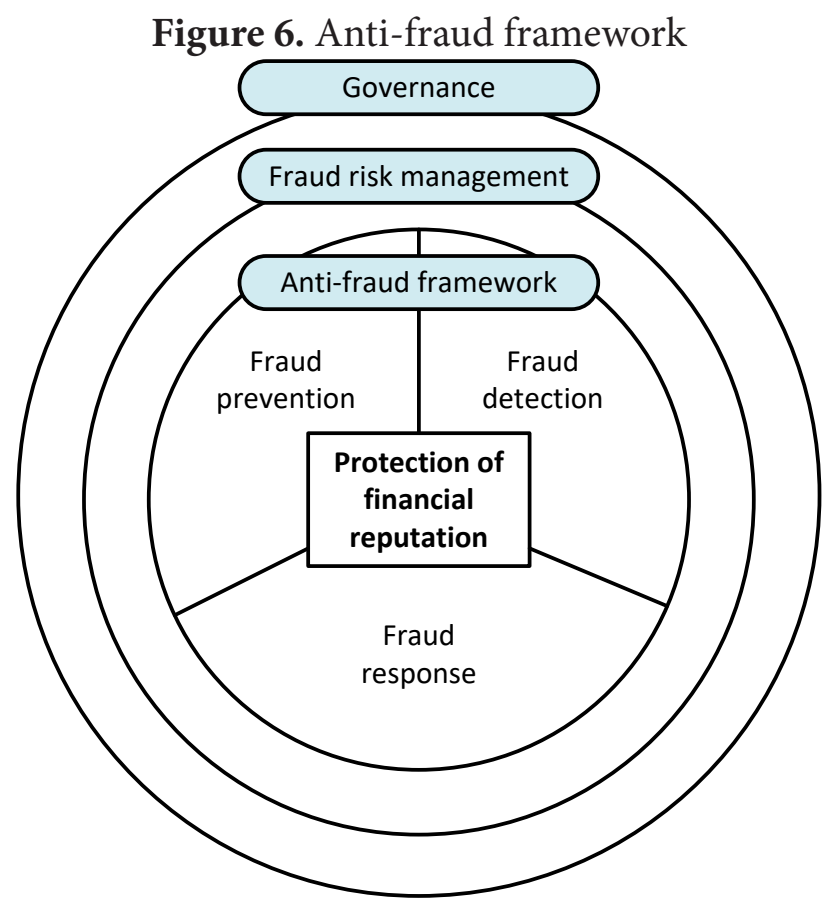

Source: Efficient Fraud Detection in Companies,

http://www.tonbeller.com/en/solutions/fraud-prevention/fraud-prevention-for-companies/

The conceptual model for developing a fraud control strategy adopted by the Australian Government (Figure 7) has four components: 1) prevention, 2) detection, 3) response, 4) monitoring, evaluation and reporting. The strategy must consider the legislative framework and adopted policies, as well as the characteristics of the management system. In addition, the strategy is influenced by ethical culture, corporate governance and the attitude of top management. Also, there should be basic conditions for effective fraud control.

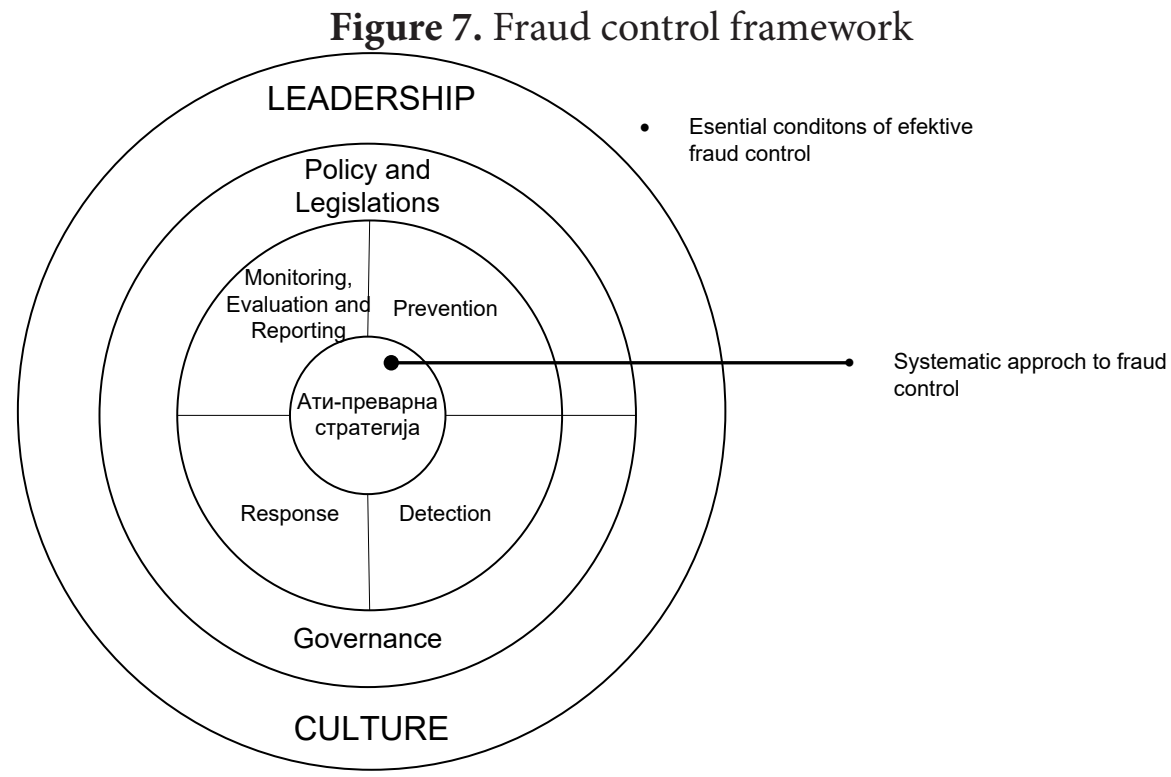

Source: Fraud Control in Australian Government Entities, 2011

Most of the conceptual frameworks are similar, but we believe that the conceptual framework developed by the Australian Government is the most complete for practical application. Based on this conceptual framework, we have developed a model for implementing an anti-fraud strategy. The model was created in a way to help organizations develop their anti-fraud strategy. The model is universal and can be adapted to all business entities, considering the specifics of business entities. 


\section{CONCLUSION}

In order to successfully implement an anti-fraud strategy, we need to know that fraud is an ethical, legal, economic and social problem. The government and management of the organization must adopt a policy of zero tolerance for fraud and encourage the development of an anti-fraud culture. Based on these elements, it is necessary to develop an anti-fraud strategy that will respect the characteristics of each organization.

The anti-fraud strategy needs to be aligned with the organization's strategy. It is especially important that the code of business ethics and the code of corporate governance are in line with the organization's strategy and anti-fraud strategy, and that the powers and responsibilities for combating fraud are clearly defined.

The leaders of the organization are most responsible for the fight against fraud, but powers and responsibilities are assigned to the board of directors, audit committee, internal audit, internal control, lower level managers and all employees in the organization.

The created model for the development of anti-fraud strategy took into account the real situation in the public sector of the Republic of Srpska and the causes of fraud, economic, legal, social and cultural system in the Republic of Srpska. The model is based on the following objectives: 1) strengthening integrity, accountability and transparency in work; 2) creating preconditions for prevention, detection, response, monitoring, evaluation and reporting of fraud, 3) development of anti-fraud culture and 4) affirmation of zero tolerance for fraud. 


\section{REFERENCES}

ACFE (2019) Global Fraud Study: Report to the Nations on Occupational Fraud and Abuse, Austin, https://www.acfe.com/report-to-the-nations/2019/

Deb, S. \& Sengupta, S. (2020). What makes the base of the pyramid susceptible to investment fraud? Journal of Financial Crime, Vol. 27, No. pp. 143-154. https://doi.org/10.1108/JFC-03-20190035

Efficient Fraud Detection in Companies, http://www.tonbeller.com/en/solutions/fraudprevention/ fraud-prevention-for-companies/

Erbuga, G., S. (2020). Rationality in decision-making and deterring corporate fraud. Contemporary Studies in Economic and Financial Analysis, Volume 102, 99-110. https://doi.org/10.1108/ S1569-375920200000102010

Homer, E. M. (2020). Testing the fraud triangle: a systematic review, Journal of Financial Crime Vol. 27 No. 1, 2020 pp. 172-187. https://doi.org/10.1108/JFC-12-2018-0136

Khadra, H. A, \& Delen D. (2020). Nonprofit organization fraud reporting: does governance matter? International Journal of Accounting \& Information Management, Vol. 28 No. 3, pp. 409428. https://doi.org/10.1108/IJAIM-10-2019-0117

KPMG (2016) Analysis of Global patterns of Fraud: Who is the typical fraudster? https://home. $\mathrm{kpmg} / \mathrm{xx} / \mathrm{en} / \mathrm{home} / \mathrm{insights/2016/05/global-profiles-of-the-fraudster.html}$

Kurpierz,J., R. \& Smith, K.(2020), The green washing triangle: adapting toolsfrom fraud to improve CSR reporting. Management and Policy Journal, https://doi.org/10.1108/SAMPJ-10-2018-0272

Maulidi, A. (2020) When and why (honest) people commit fraudulent behaviors? Extending the fraud triangle as a predictor of fraudulent behaviors. Journal of Financial Crime Vol. 27 No. 2, pp. 541-559. https://doi.org/10.1108/JFC-05-2019-0058

Nawawi, A., Saiful, A. \& Salin, A., P. (2018). Internal control and employees' occupational fraud on expenditure claims. Journal of Financial Crime. https://doi.org/10.1108/JFC-07-2017-0067

Rezaee, Z. \& Riley, R. (2014) Prijevare u financijskom izvještavanju. Zagreb: Mate. ISBN 978-953246-144-2

Sutherland, E. H. \& Cressey, D. (1992) Principles of Criminology. 11th ed. Lanham, Md.: AltaMira Press, ISBN 0-930390-69-5

Vitezić, N. (2001) Uloga i zadaci odgora za reviziju u organizaciji, Zbornik radova Interna revizija i kontrola. Zagreb-Poreč: HZRFD 